\title{
O IMPACTO DO PACTO: REFLEXOS DE UMA POLÍTICA PÚBLICA VOLTADA À EDUCAÇÃO, COM ÊNFASE NA FORMAÇÃO CONTINUADA DOS PROFESSORES DA REDE PÚBLICA
}

\author{
Fabiana Cristina Winter Eifler ${ }^{1}$, Cristiane Antonia Hauschild ${ }^{2}$
}

\begin{abstract}
Resumo: Este artigo apresenta os resultados da pesquisa que visa a investigar as modificações ocorridas no cotidiano das salas de aula de turmas do ciclo de alfabetização, com relação aos conhecimentos específicos da área de Matemática, após a participação de professores na capacitação promovida pelo Ministério da Educação - MEC, por meio do Pacto Nacional pela Alfabetização na Idade Certa PNAIC. Os pressupostos teóricos estão embasados em Imbernón (2010), Veiga-Neto (2004), Nóvoa (2003) e D'Ambrosio (1986 e 2002). É uma pesquisa de cunho qualitativo, do tipo estudo de caso. Os dados foram coletados por meio de entrevista semiestruturada, realizada com 10 sujeitos, professores da rede pública municipal de Lajeado. Os dados foram analisados por meio da Análise Textual Discursiva - ATD (Moraes e Galiazzi, 2011). Os resultados permitem inferir que o PNAIC teve impacto direto no trabalho destes professores em sala de aula do Ciclo de Alfabetização, de forma positiva, na medida em que proporcionando aprendizagens, reflexão e crescimento profissional aos docentes.
\end{abstract}

Palavras-chave: PNAIC. Formação continuada. Alfabetização Matemática. Desenvolvimento Profissional.

Abstract: This article presents the results of research aimed to investigate changes in daily classrooms in the cycle of literacy classes, with respect to specific knowledge of the Mathematics area , after teachers participation in training organized by the (Ministry of Education and Culture) Ministério da Educação e Cultura - MEC , through the Pacto Nacional pela Alfabetização na Idade Certa (National Pact for Literacy in the Right Age) - PNAIC. The theoretical assumptions are supported by Imbernón (2010) , Veiga -Neto (2004), Nóvoa (2003) and D’Ambrosio (1986 and 2002).It is a research of qualitative nature, of the case study type. Data were collected through semi-structured interviews, conducted with 10 subjects, teachers from the municipal public network in Lajeado - RS. Data were analyzed using the Discoursive Textual Analysis - ATD (Moraes and Galiazzi, 2011). Results lead to the conclusion the PNAIC had a direct impact on the work of teachers in the Literacy Cycle classroom, positively, in so far as providing learning, reflection and professional growth for teachers.

Keywords: PNAIC. Continuing Education. Mathematics Literacy. Professional development.

1 Professora.Pedagoga.fabi_eifler@yahoo.com.br

2 Professora da Univates. crishauschild@univates.br 


\section{INTRODUÇÃO}

No contexto educacional brasileiro ainda constata-se que muitas crianças concluem o período de escolaridade mínima exigida por lei sem, de fato, estarem alfabetizadas. Dados obtidos em 2003 e divulgados em 2004 (Sistema de Avaliação do Ensino Básico) ${ }^{3}$ demonstram que, $55,4 \%$ dos alunos que participaram deste processo de avaliação apresentavam sérios problemas em relação à leitura. Dos quais, $18,7 \%$ estariam em um nível 'muito crítico' pois sequer teriam desenvolvido habilidades leitoras mínimas condizentes com os quatro anos de escolarização a que estiveram submetidos e não foram adequadamente alfabetizados, pois não conseguiram responder os itens da prova de forma minimamente satisfatória.

Segundo Bossa (2002, p. 18), a análise desse aspecto, do ponto de vista social, revela que o fracasso escolar continua impondo-se de forma persistente e alarmante em nosso contexto educacional. E as ações governamentais, limitadas à ampliação das vagas no sistema público, também contribuem para a estruturação deste cenário, uma vez que não é suficiente para garantir o cumprimento daquilo a que se destina a escolarização da população, o acesso à cidadania.

Nesse contexto, em 2012, o Ministério da Educação (MEC), implementa o PNAIC - Pacto Nacional pela Alfabetização na Idade Certa, mobilizando Estados, Municípios, o Distrito Federal e engajando a sociedade brasileira como um todo, no intuito de assegurar que todas as crianças estejam alfabetizadas até os 8 anos de idade, portanto, até o final do $3^{\circ}$ ano do Ensino Fundamental.

O PNAIC é constituído por um conjunto integrado de ações, materiais e referências curriculares e pedagógicas, que passaram a ser disponibilizados pelo MEC, e sua ênfase principal, passa a ser a formação continuada de professores alfabetizadores, contribuindo para o aperfeiçoamento profissional dos educadores do ciclo de alfabetização. As ações deste Programa são baseadas em quatro eixos básicos de atuação: a realização de formação continuada, e obrigatoriamente presencial, para professores alfabetizadores, além de seus orientadores de estudo, na modalidade de tutoria; distribuição de materiais didáticos, obras literárias e de apoio pedagógico, jogos e tecnologias educacionais; realização de avaliações sistemáticas e periódicas; e, ações de gestão, controle social e mobilização.

A escolha desse tema nasce do interesse de investigar, modificações no cotidiano das salas de aula de turmas do ciclo de alfabetização, com relação aos conhecimentos específicos da área de Matemática, após a realização da capacitação promovida pelo MEC, junto aos seus professores. De forma mais específica, pretende-se abordar as influências que o PNAIC exerceu, se exerceu, e se continua exercendo sobre a prática docente dos profissionais que atuam com alunos do ciclo de alfabetização. Esta proposta de investigação tem por base a crença de que para que o educador possa

3 Mais informações em http://portal.inep.gov.br/saeb. 
exercer sua função de forma plena, é necessário que tenha clareza naquilo que ensina e de como a criança aprende. Para tanto, não se torna suficiente que o professor seja apenas um reprodutor de métodos, objetivando unicamente o domínio de um código linguístico, seja ele qual for. É necessário clareza sobre as concepções de alfabetização que fundamentam sua prática e que são inerentes a ela.

De acordo com Suely Druck (2004), enquanto presidente da Sociedade Brasileira de Matemática - SBM, o principal problema relacionado ao ensino da Matemática em nosso país, está na formação dos professores que lecionam esta disciplina e no sistema educacional que, da forma como se desenvolve, não privilegia a carreira de professor, pois não estimula a busca de novos conhecimentos e o aperfeiçoamento do desempenho profissional.

Assegurar que as políticas públicas cumpram com a função a que se destinam, nem sempre é tarefa simples. E investigar como verbas públicas são aplicadas em projetos sociais e em ações que visam melhorar a vida da população pode parecer uma tarefa difícil de ser executada, em um país com as proporções do nosso. Contudo investigar, mesmo que em pequena escala, como uma política pública influencia determinado contexto social pode ser o início de uma grande mudança social.

\section{PRESSUPOSTOS TEÓRICOS}

Nesta seção, trata-se da formação inicial e continuada dos professores e suas peculiaridades, buscando embasamento teórico em autores como Freire (2008), Imbernón (2010), Nóvoa (2003), Perrenoud (2002), e Tardif (2000 e 2002), referenciando-se os planos que regem esta instância da educação básica brasileira, como o PNE e o PDE. Na sequência apresenta-se o PNAIC, as questões organizacionais e de gerenciamento do pacto, seus objetivos e metas, complementando com uma abordagem acerca das questões da Alfabetização Matemática em si, trazendo referenciais pautados em D’Ambrosio (1986, 2002), Oliveira (2009), Kamii (2005) e Veiga-Neto (2004), que, dentre outros, tratam da ludicidade, da construção do conhecimento e de sua contextualização com o cotidiano infantil.

Em se tratando de formação profissional, os tempos atuais exigem da profissão de professor novas demandas e encaminhamentos. Entre tantas dificuldades encontradas estão o fato de ser encarada como vocação e não como opção profissional, além do comportamento da sociedade em não reconhecer a capacidade de autonomia das escolas, considerando-as como território onde qualquer um pode inserir-se para desempenhar a função docente, onde a qualificação não tem o papel que possui em outras áreas. Tais condições reduzem a profissão de professor a uma subprofissão.

Para Imbernón (2010b, p.7), a docência perdeu sua função basicamente transmissiva, para se dar nas relações de interação, de convivência, de cultura contextual, e na 
heterogeneidade social, envolvendo todos os sujeitos do processo educativo. Perrenoud (2002) afirma que:

A formação de "profissionais reflexivos" deve se tornar um objetivo explícito e prioritário em um currículo de formação de professores; em vez de ser apenas uma familiarização com a futura prática, a experiência poderia, desde a formação inicial, assumir a forma simultânea de uma prática "real" e reflexiva. (PERRENOUD, 2002, p. 104)

A qualificação dos professores se faz necessária, como processo, para uma atuação efetiva, de qualidade e que seja capaz de atender as demandas dos contextos sociocultural e econômico em que se inserem. Contextos estes, que além de heterogêneos, estão em permanente mutação, exigindo do educador a capacidade de inovação. De acordo Imbernón (2010a), a docência só poderá ser encarada como profissão a partir do instante em que o exercício da mesma e os conhecimentos gerados por sua prática propiciem mudanças de postura e a dignificação da pessoa, tomando por base sua natureza e condição.

Para contribuir com a qualificação dos professores e, consequentemente, da educação brasileira, surge no cenário nacional o PNAIC, com o objetivo de assegurar que todas as crianças estejam alfabetizadas até os 8 anos de idade, ou seja, ao final do $3^{\circ}$ ano do Ensino Fundamental. O PNAIC considera quatro princípios centrais: o sistema de escrita alfabética é complexo e exige um ensino sistemático e problematizador; o desenvolvimento das capacidades de leitura e de produção de textos deve ser iniciado logo no início da Educação Básica; conhecimentos oriundos das diferentes áreas podem e devem ser apropriados pelas crianças, de modo que elas possam ouvir, falar, ler, escrever sobre temas diversos e agir na sociedade; e a ludicidade e o cuidado com as crianças são condições básicas nos processos de ensino e de aprendizagem.

A criação do PNAIC teve como intuito acolher somente os professores que atuam com o chamado ciclo de alfabetização. Sendo que podem participar professores cujos municípios estejam cadastrados junto ao MEC, para esta formação. A qualificação mínima dos educadores deve ser formação pedagógica ou licenciatura. Porém a procura e a tentativa de adesão dos professores de outras séries ao Programa evidenciam seu sucesso, pois conforme os dados oficiais do MEC foram mais de 650 estudantes universitários, além de 318.465 professores alfabetizadores e um investimento de R\$ 3.3 milhões. No ano de 2014 houve a inclusão da disciplina de Matemática, com previsão de posterior contemplação à disciplina de Ciências em 2015.

É indispensável frisar a importância das atividades práticas no ensino da Matemática em qualquer nível, pois são referência para o ensino da disciplina e que, relacionar a teoria com a prática é um dos caminhos para se obter um ensino de qualidade, em que os alunos consigam entender e visualizar de forma mais clara e concreta o que lhes é aplicado por meio da teoria. Para tanto, se faz necessária uma formação adequada dos 
professores, com a intenção de conscientizá-los da sua importância no processo ensinoaprendizagem e na formação do aluno.

D’Ambrósio salienta que:

O valor da teoria se revela no momento em que ela é transformada em prática. No caso da educação, as teorias se justificam na medida em que seu efeito se faça sentir na condução do dia-a-dia na sala de aula. De outra maneira, a teoria não passará de tal, pois não poderá ser legitimada na prática educativa. (D`AMBROSIO, 1986, p. 43).

Da mesma forma, Veiga-Neto (2004, p. 02), afirma que a relação problemática entre teoria e prática é falsa, ou em suas palavras, é um "falso-problema", pois a priori, é evidente a necessidade da coexistência, da completude e da relação somatória entre ambas, pois uma não se faz sem a outra, e desta forma não existe relação hierárquica entre elas. Teoria e prática se completam e se permeiam de maneira que fica impossível sua dissociação.

[...] eu quero dizer que a não solução do conflito teoria $\mathrm{x}$ prática não decorre da dificuldade do problema, nem de uma suposta incapacidade humana em dar conta dele e nem mesmo do fato de que ainda é cedo ou que não se trabalhou bastante para se chegar a uma solução. (VEIGA-NETO, 2004, p.2).

Oliveira (2009) destaca que os professores deveriam ser capacitados para a prática lúdica, com investimentos das escolas nesta direção. Sendo assim, percebe-se a necessidade de constante atualização por parte dos professores, para que os mesmos transformem sua práxis, fazendo dela uma ação didática, voltada às vivências lúdicopedagógicas, com vistas ao caráter lúdico do ser humano, transformando a construção dos saberes e conhecimentos em fonte de prazer e alegria, e, em especial, no processo de desenvolvimento infantil dentro do ambiente escolar.

\section{PROCEDIMENTOS METODOLÓGICOS}

Esta seção tem por objetivo apresentar os procedimentos metodológicos desta pesquisa, pois faz-se necessário que esses estejam bem definidos e que haja "afetuosidade e entrosamento" na relação entre o pesquisador e o objeto de seu estudo, bem como na prática da docência. É esta "afetuosidade" que garantirá o sucesso em qualquer jornada a que nos propusermos.

A metodologia, segundo Andrade (2007, p. 119), “(...) é o conjunto de métodos ou caminhos que são percorridos na busca do conhecimento". Portanto, por meio desta pesquisa, busco verificar que modificações ocorreram no fazer pedagógico diário de professores do ciclo de alfabetização de duas escolas da rede municipal de Lajeado que participaram do PNAIC, considerando este um importante Programa de formação 
continuada de professores alfabetizadores. Deste modo, esta pesquisa caracteriza-se como uma pesquisa de cunho qualitativo, do tipo estudo de caso.

Para dar prosseguimento ao desenvolvimento de uma pesquisa é necessária a utilização de um olhar atento aos contextos a nossa volta, lançando mão de uma contraposição entre os dados coletados, informações levantadas a respeito do assunto sobre o qual voltamos nossa atenção, confrontando-os com o conhecimento teórico produzido a respeito daquilo a que nos propomos pesquisar. Esse olhar mais qualitativo e eficiente, no que tange a pesquisa em educação, tem por objeto contribuir para resultados com maior coerência e "(...) suficientes para pensarmos as soluções mais adequadas aos nossos problemas (...)" (Lüdke e André, 1986, p. 8). De acordo com essa perspectiva, uma pesquisa voltada à educação deve ser de caráter investigativo, interativo e social, para que desta forma os resultados oriundos da mesma possam contribuir no sentido de propor mudanças no sistema educacional, provocando reflexões, encaradas como pertinentes ao contexto.

Ainda conforme Lüdke e André (1986), na investigação qualitativa, o estudo de caso apresenta sete características: visa à descoberta, na medida em que podem surgir, a qualquer momento da pesquisa, novos elementos e aspectos importantes para a mesma; dá ênfase, entre outros aspectos, à interpretação do contexto, pois são levadas em conta as características do espaço em que ocorrem, neste caso as escolas, o meio social em que se inserem e os recursos materiais e humanos disponíveis; retrata a realidade ampla e profundamente; faz uso de uma variedade de fontes de informação; permite generalizações naturalistas; procura representar as diferentes perspectivas presentes numa situação social; e, por fim, utiliza uma linguagem e uma forma mais acessível do que outros métodos de investigação.

Yin, ao abordar estratégias de pesquisa, afirma que:

Como estratégia de pesquisa, utiliza-se o estudo de caso em muitas situações, para contribuir com o conhecimento que temos dos fenômenos individuais, organizacionais, sociais, políticos e de grupo, além de outros fenômenos relacionados. (YIN, 2005, p. 20)

Em adição, o autor afirma também que a metodologia do estudo de caso faz-se valer como estratégia mais adequada quando o foco de uma pesquisa concentra-se em aspectos da vida real em um contexto contemporâneo. Sendo assim, analisar o impacto promovido pelo PNAIC da Matemática no dia-a-dia das salas de aula de duas escolas da rede Municipal de Lajeado, por meio de estudo de caso, pode ser considerado eficaz, na medida em que se apresentam, nas situações reais e cotidianas do contexto da docência, as inovações e desafios educacionais propostos por esta política pública de formação continuada.

A coleta de dados consistiu em realização de entrevista semiestruturada com 10 professores cursistas, de duas escolas públicas da rede municipal de Lajeado. Concluído 
o período de realização das entrevistas, o trabalho prosseguiu com a transcrição e posterior análise e categorização dos dados averiguados, por meio de Análise Textual Discursiva - ATD. Neste processo reúne-se as unidades de significado semelhantes, o que pode gerar vários níveis de categorias de análise. Segundo Moraes e Galiazzi (2011, p. 78) "a categorização é um processo exigente e que requer esforços e envolvimento. Além de um retorno constante às informações, também exige uma atenção permanente aos objetivos e metas da pesquisa".

Realizar uma pesquisa que tome como forma de análise a ATD, de acordo com Moraes e Galiazzi (2011) "[...] é envolver-se em um processo coletivo de reconstrução de significados.”. Este processo permite ao pesquisador a apropriação do conhecimento ao mesmo tempo em que lhe dá a possibilidade de proceder, com maior perspectiva de sucesso, enfrentamentos na direção da transformação social.

\section{ANÁLISE E DISCUSSÃO DOS DADOS}

Esta seção apresenta os resultados obtidos por meio da ATD das entrevistas semiestruturadas realizadas para esta pesquisa que visa responder ao problema desta pesquisa que pretendeu investigar: Que modificações ocorreram no fazer pedagógico diário de professores do ciclo de alfabetização, de duas escolas da rede municipal de Lajeado, que participaram do PNAIC da Matemática?

Da análise das entrevistas, emergiram 3 categorias. A primeira, Formação continuada: somando esforços, diminuindo angústias, multiplicando resultados e dividindo anseios, retrata, como o próprio enunciado diz, os anseios, desejos, expectativas e angústias, comumente compartilhados por profissionais da educação. A segunda, Articulando o conceito com a ação: a teoria na prática reforça a ideia da articulação entre teoria e prática. E por fim, a terceira, Impactou?: $\mathrm{O}$ fazer pedagógico pós PNAIC, elenca as mudanças articuladas, pós - formação, no fazer pedagógico diário dos professores.

Os sujeitos da pesquisa, em número de 10, são professores da Rede Pública Municipal de Educação de Lajeado, que atuam em duas escolas de Ensino Fundamental, sendo que uma delas é organizada por ciclos de aprendizagem, da qual cinco professores foram entrevistados, e a outra tem sua organização baseada na seriação, onde, igualmente, cinco professores tiveram participação nesta pesquisa. Os mesmos serão identificados por P1, P2, P3, P4, P5, P6, P7, P8, P9 e P10, como forma de preservar o anonimato dos mesmos.

Quanto ao perfil, todos os sujeitos da pesquisa possuem como formação inicial o curso Normal. Porém, quanto à formação acadêmica a única exceção é P10, que não a possui. Contudo, sete professores são formados em Pedagogia, um em Letras e um em Ciências Biológicas. Além disso, outro fator a considerar é o tempo de experiência profissional destes professores, que varia entre 10 e 32 anos. 
Foi possível constatar que existe, entre a maioria dos indivíduos entrevistados, um perfil pouco variável no que tange ao tipo de formação e ao tempo de trabalho. Isso nos permite verificar que os professores, mesmo após diversos anos de atuação na educação, buscam por Formações Continuadas que visem e possibilitem a atualização e reformulação de suas práticas cotidianas em sala de aula.

Quanto à primeira categoria emergente, Formação continuada: somando esforços, diminuindo angústias, multiplicando resultados e dividindo anseios, revela a expectativa dos professores, por vezes não correspondida, quanto à oferta e organização de programas de formação continuada. Além disso, ressalta a metodologia utilizada nas formações do PNAIC, na contramão das demais, como positiva e satisfatória. Ao analisar as entrevistas dos sujeitos da pesquisa, emergem verbalizações de anseios, desejos, expectativas e angústias, comumente compartilhados por profissionais desta área há várias décadas.

Segundo Carvalho e Ramoa (2000), a formação continuada, desenvolvida no âmbito acadêmico/escolar, transforma-se em:

[...] espaço de experimentação e reavaliação das ações investigativas empreendidas por cada indivíduo singular e devolvidas ao grupo de forma a permitir uma reapropriação dos saberes, mas também uma nova perspectiva exploratória do estudo realizado. (CARVALHO e RAMOA, 2000, p. 8)

A partir disso, a pesquisadora constatou que as necessidades dos educadores, de forma geral, variam pouco ou quase nada. Pois nove, entre os dez, de forma contundente, afirmam que um dos aspectos positivos, que merecem destaque, neste processo de formação continuada, foi a possibilidade de troca de experiências e de materiais. Poder perceber no trabalho do colega algum traço que possa ser aplicado no seu próprio trabalho ou que respalde sua prática profissional, faz com que o professor se tranquilize e também queira explanar o seu próprio jeito de fazer. Isto fica evidenciado, inicialmente, na fala de P1:

Eu acho que é justamente esta troca de experiências, o que tá dando certo nas escolas, que a gente tem esta oportunidade de compartilhar. É o que tá dando certo na minha com o que tá dando certo na outra, então a gente tem a oportunidade de aperfeiçoar a prática da gente. (P1)

E, em posterior declaração de $\mathrm{P} 4$, onde expõem a expectativa da maior parte dos professores com relação às Formações Continuadas de modo geral:

Ai... negativo? Acho que não, mas positivo muitos. A começar pela qualidade da formação que foi muito boa e depois, os professores receberem pra fazer atualização? Isso é muito bacana......Muita troca, muita parceria, muita dica, muita coisa nova e aplicável, que é o que a gente quer nestas formações. Foi muito bom mesmo. (P4) 
Além disso, a necessidade dos professores de buscar novos conhecimentos é confirmada quando, unanimemente, estes reafirmam suas intenções de novas participações nas Formações Continuadas ofertadas pelo PNAIC, no caso de continuidade das propostas do Programa. O que, nas entrelinhas, também pode ser lido como um sinal de aprovação à qualidade desta modalidade de trabalho, no que tange a sua estrutura e forma de organização, pois raras foram as críticas aqui apresentadas. Dentre elas, é pertinente destacar a fala de P3, quando questionada a respeito dos aspectos positivos e negativos desta formação, onde relata o seguinte depoimento:

O que eu achei é que as vezes não ficou muito claro, porque a gente gosta de saber assim,
ob, o que é o certo. Tinha assuntos, por exemplo, cálculos por decomposição: "ah, o aluno,
ele não precisa iniciar o cálculo pela unidade pra resolver, ele pode começar a resolver pela
centena, tanto faz...". Na minha opinião não, porque depois, quando ele tiver a reserva
e o empréstimo como é que vai funcionar se ele começou por lá? Então isso, assim eu não
concordava. Esse lado, assim que as vezes bom, alguns assuntos aspectos ficaram um pouco
na dúvida, a gente não teve esclarecimentos, mas assim, no geral foi muito bom. (P3)

Por meio de falas como essa, percebe-se que o professor, em seu processo de aperfeiçoamento, também estabelece suas próprias interpretações e construções, sem limitar-se apenas ao discurso trazido de fora para dentro. O professor passa a configurar como autor/ator de seu conhecimento, de seu processo de crescimento profissional. Esta constante busca pelo aperfeiçoamento é inerente à profissão educadora.

Segundo Nóvoa (2003, p.23) "O aprender contínuo é essencial e se concentra em dois pilares: a própria pessoa, como agente, e a escola como lugar de crescimento profissional permanente". Neste sentido, é possível afirmar que, a formação continuada deve se dar na coletividade, pois carrega em sua essência a necessidade do compartilhamento de experiências, além da reflexão como instrumento imprescindível a análise contextual.

Para que uma formação continuada atinja seu objetivo maior, necessita ser impregnada de significados para o professor. As propostas apresentadas para o aperfeiçoamento dos docentes brasileiros, têm apresentado baixos índices de eficiência, pois entre outros agravantes, normalmente desvinculam teoria e prática, além de enfatizar, em demasia, aspectos normativos. O que concorre para o desinteresse e reações de descrédito por parte dos professores, por constatarem que, de forma geral, as iniciativas que se apresentam como oportunidades de formação e qualificação profissional, na maior parte das vezes, em nada contribuem para tanto. Situação que pode ser ilustrada com um fragmento do depoimento de P2: “... A gente participou por que a gente foi obrigado, no municipio de Cruzeiro, que era onde eu trabalhava na época". Esta sensação de esvaziamento dos programas de formação continuada é o sentimento que tem acompanhado muitos professores no decorrer de sua formação. Contudo, na contramão destes eventos, surge no cenário nacional o PNAIC, e fica evidenciado o diferencial, quando todos os professores entrevistados afirmam que, no caso de oferta de novos módulos, participariam sem hesitação, como relata P5: 
Sempre... é tudo de bom. É uma formação que te dá vontade de se envolver, além de ser gratuita e que, bem ou mal, te paga pra participar. Dá pra dizer que uma proposta destas é uma coisa nova, nunca feita antes. Pelo menos eu não me lembro. (P5)

Um Programa de formação continuada, por mais amplo e abrangente que seja, dificilmente contempla plenamente as necessidades de todos os docentes que dele participam, dada a heterogeneidade do grupo. Deve-se considerar, nesta análise, que cada indivíduo possua uma história pessoal e profissional singular. No entanto, Candau (1997) apresenta três aspectos fundamentais para um processo de formação continuada de professores mais eficaz: a escola, como espaço privilegiado de formação; a valorização do saber docente; e a "bagagem" de vida dos professores. Isto equivale dizer que uma formação continuada de qualidade deve atentar necessariamente para os seguintes fatores: primeiro, as necessidades reais do cotidiano escolar do professor, usando-as como ponto de partida para a elaboração de um Programa eficaz; segundo, valorização do saber curricular e disciplinar, somado ao saber da experiência de vida e as heranças culturais dos indivíduos envolvidos; e terceiro, mas não menos importante, valorização e resgate do saber docente, construído na prática pedagógica diária, engendrando a articulação entre teoria e prática.

$\mathrm{Na}$ segunda categoria reforça-se a ideia da articulação entre teoria e prática, pois, assim como salientam Pimenta e Ghedin (2012, p. 25-26), não pode cometer o engano de imaginar que somente a reflexão da prática e sobre ela, serão suficientes para o encaminhamento adequado e resolução de todos os problemas enfrentados no fazer pedagógico. Estabelecer enlaces entre teoria e prática, no trabalho cotidiano, dá sustentação e significância ao fazer pedagógico. E este suporte necessita ser ofertado, não apenas nos programas de formação continuada, mas em todo o processo formativo dos docentes. Processo este que deve ser constante e permanente. Segundo os autores:

[...] a formação contínua não se reduz a treinamento ou capacitação e ultrapassa a compreensão que se tinha de educação permanente. A partir da valorização da pesquisa e da prática no processo de formação de professores, propõe-se que esta se configure como um projeto de formação inicial e contínua articulado entre as instâncias formadoras (universidade e escolas). (PIMENTA E GHEDIN, 2012, p. 25-26)

Os professores entrevistados deixam transparecer, em seus depoimentos, a sua preocupação em articular teoria e prática e isto é unanime entre eles. Para eles a formação continuada ofertada com o PNAIC, possibilitou esta articulação entre teoria e prática, na medida em que propiciou a exploração de materiais fornecidos pelo MEC de forma interativa, oportunizou e incentivou a própria produção de materiais pelos cursistas, além de possibilitar o compartilhamento de todas as questões trazidas por eles, de forma direta e dinâmica. A partir disso, fica de forma muito nítida, explicitada a importância da produção da Caixa Matemática, durante o processo da formação, e a utilização da mesma dentro de sala de aula, como consequência direta e positiva de todo o trabalho desenvolvido durante os meses de andamento da formação. 
Esta percepção encontra suporte em Reame et al. (2012, p. 77), quando argumenta que "[...] a exploração de jogos de regra tem um papel de destaque no desenvolvimento de capacidades representativas, da criatividade e imaginação, de habilidades de compreensão e expressão, da linguagem oral, de conceitos, entre outros aspectos." Devemos então, levar em consideração a grande importância dos jogos como instrumento de aprendizagem, não apenas no processo de alfabetização, mas em todo o processo educativo, o que passa a ser reiterado por Piaget (1976, p. 160), quando afirma que:

O jogo é, portanto, sob as suas formas essenciais de exercício sensório-motor e de
simbolismo, uma assimilação do real à atividade própria, fornecendo a esta seu
alimento necessário e transformando o real em função das necessidades múltiplas
do eu. Por isso, os métodos ativos de educação das crianças exigem que se forneça às
crianças um material conveniente, a fim de que, jogando elas cheguem a assimilar
as realidades intelectuais que, sem isso, permanecem exteriores à inteligência
infantil.

Fica evidenciado, que o jogo desempenha uma função propulsora do processo de desenvolvimento e aprendizagem infantil, pois a criança imersa em um ambiente de constantes mudanças e descobertas, interagem de forma dinâmica com o mesmo. E é nesse contexto que o jogo passa a ser o instrumento legítimo da aprendizagem, na medida em que auxilia na construção de novas descobertas, contribuindo para o desenvolvimento e enriquecimento cognitivo, deste ser em formação, além de propiciar a interação com seus pares, para além dos sujeitos constituintes de seu meio. Pois assim como afirma D’Ambrósio (2002, p.24), "o processo de gerar conhecimento como ação é enriquecido pelo intercâmbio com outros, imersos no mesmo processo, por meio do que chamamos comunicação."

O jogo empregado como promotor da capacidade e potencialidade da criança, deve ocupar lugar privilegiado na prática pedagógica diária em sala de aula, tornando este ambiente em espaço facilitador de aprendizagens, de modo a auxiliar o professor na mediação destes processos. Isso é confirmado por Dinello (1997, p. 26) "pelo jogo, a psicomotricidade da criança se desenvolve num processo prático de maturação e de descobrimento do mundo circundante."

Pode-se, então afirmar que o jogo desempenha um papel de grande importância no desenvolvimento psicomotor infantil e favorece aquisições mais elaboradas. Oliveira (1999, p. 12) reitera essa afirmação ao salientar que:

Muitas das dificuldades apresentadas pelos alunos podem ser facilmente sanadas no âmbito da sala de aula, bastando para isto que o professor esteja mais atento e mais consciente de sua responsabilidade como educador e despenda mais esforço e energia para ajudar a aumentar o potencial motor, cognitivo e afetivo do aluno. 
Com isso, é válido afirmar que ao estabelecermos um Programa que estimule a atividade psicomotora, conferindo destaque especial ao jogo, privilegiamos o desempenho psicomotor da criança, na mesma medida em que, favorecemos a capacidade de concentração, o enfoque da atenção, o entrosamento entre os pares e estimulamos a imaginação. Como resultado deste investimento, teremos alunos autônomos, pensantes e com a autoestima elevada.

$\mathrm{O}$ investimento em atividades que estimulem a autonomia, desenvolvam a capacidade de raciocínio e elevem a autoestima dos educandos, traz a vantagem de tornar o trabalho mais lúdico. Sendo assim, esta categoria emergente - terceira e última -, salienta modificações que foram desencadeadas na prática diária, nas aulas de Matemática, dos professores entrevistados, que passaram a ser realizadas a partir da formação continuada propiciada pelo PNAIC.

Rememorando Fernández (2001, p.29) que afirma que "entre o ensinante e o aprendente abre-se um campo de diferenças onde se situa o prazer de aprender", buscou-se nas falas dos entrevistados, indícios de práticas deste tipo, mostras destas modificações, e destaca-se, a título de comprovação das mesmas, excertos de P4, P5, P7, P8, P9 e P10 que afirmam, de forma explícita, que realmente passaram a "fazer de um jeito diferente":

"Claro! Passei a trabalhar de forma mais, digamos assim, descontraída, lúdica mesmo. Antes eu usava jogos quando sobrava tempo, agora uso quase todos os dias, ao menos 3 vezes por semana é certo." (P4)

"Sim, sem dúvida. Passei a usar mais jogos e atividades lúdicas. O jogo passou a ter lugar de destaque nas minhas salas de aula. Inclusive criei algumas atividades para explorar melhor os jogos que conheci e passei a procurar coisas novas pra trazer novidades sempre que consigo." (P5)

“Sim... no meu comportamento, no meu modo de ver a Matemática, principalmente, eu ressalto isso, no modo de como trabalhar a Matemática e a importância dos jogos e das novas ideias que foram adquiridas no decorrer do curso de alfabetização." (P7)

"Com certeza. Em aspectos de jogos, de atividades, enfim, até de um reforço de um conhecimento teórico.” (P8)

"Eu que, tanto na Matemática quanto na Linguagem, é tudo que tu sabe, mas que tu acaba deixando de lado. Eu sempre dava um jeitinho de usar, mas eu passei a usar mais. Uma vez por semana eu tenho junto os jogos, por que, o que que acontece, é importantíssimo mas tu acaba pensando a eu preciso... até que pega material, até que guarda material, tu pensa no tempo que tu sempre vai ter que disponibilizar. Mas agora assim, a gente vai ter um momento pra isso, a gente joga os jogos da 
Matemática ou da Linguagem e sempre vai usando por que é um momento de muita construção diferente, mas eu acho que a gente explora muito mais coisas. Agora eu tenho mais consciência disso, antes eu sempre acabava, assim, deixando para o tempo que sobrava, se sobrava. As vezes de uma semana deixava pra outra e se a gente tivesse mais trocas, a gente ia ver o quanto ele é importante, por que tem criança que é através dali que vai despertando." (P9)

"Posso dizer que sim. Muitas coisas eu já desenvolvia, talvez não tão explorado mas já fazia. Minhas crianças realmente estão aprendendo melhor e com mais prazer." (P10)

Este "jeito de fazer diferente" aquilo que já se fazia anteriormente, só é possível quando o professor se encanta com o que faz e percebe que pode fazer melhor. Se o professor se deixa contagiar pelo encantamento de "aprender a ensinar" ele se permite evoluir em seu fazer profissional. Para Fernández (2001, p. 36):

Aprender é apropriar-se da linguagem; é historiar-se, recordar o passado para despertar-se ao futuro; é deixar-se surpreender-se pelo já conhecido. Aprender é reconhecer-se, admitir-se. Crer e criar. Arriscar-se a fazer dos sonhos textos visíveis e possíveis. Só será possível que os professores possam gerar espaços de brincar-aprender para seus alunos quando eles simultaneamente os construírem para si mesmos.

Buscar na própria prática novas formas de fazer o que já se fazia, suscita no educador o sentimento de autoria, desencadeando novas possibilidades e fomentando a necessidade de novas conquistas, novas experiências, novas construções e interrelações com o ato de ensinar. Pois, ainda de acordo com Fernández (2001, p.106), "[...] precisamos disseminar a ideia de pensar e entrelaçá-la com a experiência, a ação, a transformação. Pensar implica, necessariamente, transformar (se).” E, ao perceber em sua prática novas possibilidades, o professor passa a transformar (se). O resultado disso? O prazer de ensinar e o prazer de aprender passam a andar lado a lado, garantindo uma aprendizagem efetiva e de qualidade.

Em resumo, fica evidente que as mudanças que ocorrem no fazer pedagógico dos sujeitos desta pesquisa, após a formação continuada ofertada pelo PNAIC, em muito estão contribuindo para a qualificação da educação, no micro contexto analisado, e sendo assim, ousa-se subentender que no macro contexto (no Brasil como um todo) esta realidade também tem se modificado.

\section{CONSIDERAÇÕES FINAIS}

Neste artigo teve-se o propósito de apresentar os resultados da pesquisa que pretendeu investigar influências/modificações no cotidiano das salas de aula de turmas do ciclo de alfabetização, com relação aos conhecimentos específicos da área de 
Matemática, após a realização da capacitação promovida pelo MEC, junto aos seus professores, capacitação esta, desenvolvida como uma das propostas do PNAIC.

Para que o trabalho lograsse, êxito foi necessário uma escuta atenta e imparcial dos depoimentos dos professores participantes da pesquisa, de forma a melhor compreender a dimensão da proposta trazida pelo PNAIC, bem como das expectativas destes educadores com relação à formação continuada de modo geral. Além disso, foi primordial um aprofundamento teórico na busca de embasamentos que sustentassem as conclusões oriundas da análise destas fontes.

O envolvimento das pesquisadoras com este trabalho foi desafiador e, na mesma proporção, gratificante, pois constatar que uma política pública, pensada e desenvolvida para a elevação da qualidade educacional de nosso país, com ênfase no processo de alfabetização, superou as expectativas de seu público alvo, faz com que possamos cultivar o sonho de um dia vermos a Educação Brasileira configurar destaque entre as melhores do mundo. Evidentemente, isso ainda é um sonho distante, mas nos atrevemos a pensar que estamos trilhando caminhos mais adequados neste sentido.

É fundamental esclarecer que, embora a formação continuada deva atender às necessidades do professor no seu fazer pedagógico diário, ela não pode ser encarada como um receituário ou um manual, com um roteiro do tipo "passo-a-passo", ou, pedagogicamente falando, um conjunto de modelos metodológicos, uma lista de conteúdos que, ao serem seguidos à risca, serão a solução para todos os problemas de aprendizagem de nosso alunado e garantirão o êxito de todos ao final do processo. Muito embora alguns professores procurem justamente este tipo de "auxílio" nos cursos de aperfeiçoamento dos quais participam.

Ousa-se afirmar que a formação continuada passa a ser significativa e reflete uma nova postura no professor quando consegue, a exemplo do constatado nesta pesquisa, formar um professor profissionalmente competente, assegurando a ele a possibilidade de atuar, de forma eficaz, com os recursos de que dispõe. Além disso, uma formação continuada de qualidade deve ser capaz de dotar o professor de uma fundamentação teórica consistente, e capacitá-lo a tomar consciência dos aspectos externos que interferem na educação, uma vez que a prática educativa não se restringe à sala de aula ou à escola, mas se dá em um contexto maior, cujas situações e eventos interferem diretamente no seu andamento e, consequentemente, no seu resultado.

Cabe, salientar, o quão importante foi o PNAIC, para a melhoria da qualidade do processo educativo no Ciclo de Alfabetização, lembrando que esta iniciativa requer continuidade, uma vez que houve unanimidade entre os participantes desta pesquisa, na afirmação de que participarão sim, se novos módulos forem ofertados.

E no "final das contas", conquista maior se dá quando ouve-se um professor afirmar com entusiasmo na voz: "Minhas crianças realmente estão aprendendo melhor e com mais prazer", afinal este é o nosso maior objetivo. 


\section{REFERÊNCIAS}

ANDRADE, Maria Margarida de. Introdução à metodologia do trabalho científico: elaboração de trabalhos na graduação. 8. ed. São Paulo: Altas, 2007.

BOSSA, Nadia A. Fracasso escolar - um olhar psicopedagógico. Porto Alegre: Artes Médicas, 2002

CANDAU, Vera Maria. Formação continuada de professores: tendências atuais. In:

CANDAU, V. M. (Org.). Magistério: construção cotidiana. Petrópolis: Vozes, 1997, p.51-68.

CARVALHO, Angelina e RAMOA, Manuela. Dinâmicas da formação: recentrar nos sujeitos, transformar os contextos. Porto: Asa, 2000.

D’AMBROSIO, Ubiratan. Educação matemática: Da teoria à prática. Campinas, SP: Papirus, 2002.

Da realidade à ação: reflexões sobre educação e matemática. $5^{\mathrm{a}}$ ed. São Paulo: Summus,1986.

DINELLO, Raimundo. Expressão lúdica criativa. 6a ed. Uberaba: Universidade de Uberaba; 1997.

DRUCK, S. Entrevista ao Jornal da Ciência, on-line, 16/02/2004, http://www. jornaldaciencia.org.br/Detalhe.jsp?id=16299, acesso em 10/03/2016.

FERNÁNDEZ, Alicia. O saber em jogo: a psicopedagogia propiciando autorias de pensamento. Porto Alegre: Artmed Editora, 2001.

IMBERNÓN, Francisco. Formação continuada de Professores. Porto Alegre: Artmed, 2010a.

. Formação Docente e Profissional: formar-se para a mudança e a incerteza. 8. ed. São Paulo: Cortez, 2010b.

KAMII, Constance. Crianças pequenas continuam reinventando a aritmética séries iniciais: Implicações da teoria de Piaget. 2 ed. Porto Alegre: Artmed, 2005.

LUDKE, Menga e ANDRÉ, Marli. Pesquisa em educação: Abordagens educativas. São Paulo: Epu, 1986.

MORAES, Roque e GALIAZZI, Maria do Carmo. Análise textual discursiva. 2 ed. rev. Ijuí: Ed. Unijuí, 2011.

NÓVOA, António. Cúmplices ou reféns? Nova Escola. São Paulo: Abril; n. 162, p. 14-15, mai. 2003.

OLIVEIRA, M.A.C. Psicopedagogia: a instituição em foco. Curitiba: IBPEX, 2009.

OLIVEIRA, Gislene de Campos. Psicomotricidade: educação e reeducação num enfoque pedagógico. 3 ed. Petrópolis, RJ: Vozes, 1999. 
PERRENOUD, Philippe. A prática reflexiva no ofício de professor: profissionalização e razão pedagógica. Porto Alegre: Artmed, 2002.

PIAGET, Jean. Psicologia e pedagogia. Trad. Lindoso DA, Ribeiro da Silva RM. Rio de Janeiro: Forense Universitária;1976.

PIMENTA, Selma Garrido; GHEDIN, Evandro (Orgs.). Professor reflexivo no Brasil: gênese e crítica de um conceito. São Paulo: Cortez, 2012.

REAME, Eliane et al. Matemática no dia a dia da Educação Infantil: rodas, cantos, brincadeiras e histórias. São Paulo: Saraiva, 2012.

TARDIF, M. Os professores enquanto sujeitos do conhecimento: subjetividade, prática e saberes no magistério. In: CANDAU, Vera Maria (org.). Didática, currículo e saberes escolares. Rio de Janeiro: Dp \& A editora, 2000.

. Saberes docentes e formação profissional. São Paulo: Vozes, 2002.

VEIGA-NETO, Alfredo. Equívocos ou o (falso) problema da relação entre teoria e prática, na formação docente. Resumo expandido de uma apresentação e discussão na Ulbra, Canoas, 2004.

YIN, Robert. Estudo de Caso: planejamento e métodos. 3. ed. Porto Alegre: Bookmann, 2005. 